\title{
Premature Atherosclerosis, and Arterial stiffness as a Challenge in Rheumatoid Arthritis
}

\author{
Mary Wadie Fawzy \\ Faculty of Medicine, Cairo University, Egypt
}

"Corresponding author: Mary Wadie Fawzy, Faculty of Medicine, Cairo University, Egypt, Tel: 002 01006196952; E-mail: drmarywadie@yahoo.com

Rec date: August 17, 2015; Acc date: August 26, 2015; Pub date: September 08, 2015

Copyright: (C) 2015 Fawzy MW. This is an open-access article distributed under the terms of the Creative Commons Attribution License, which permits unrestricted use, distribution, and reproduction in any medium, provided the original author and source are credited.

\section{Introduction}

Patients with rheumatoid arthritis (RA) have an increased morbidity and mortality due to cardiovascular disease (CVD) [1]. Traditional cardiovascular $(\mathrm{CV})$ risk factors cannot fully explain the increase but inflammation has been shown to contribute to the increased CVD among these patients [2]. The pro-inflammatory cytokines such as tumor necrosis factor alpha and interleukin-6, involved in the pathogenesis of RA, are also independently predictive of subsequent cardiovascular disease (CVD). In RA, inflammation alters HDL constituents and the concentration of LDL and HDL, thus facilitating atherosclerosis and CVD events. On the other hand, also the increase of oxidative processes, frequently observed in RA, induces atherosclerosis. Interestingly, some genetic polymorphisms associated with RA occurrence enhance atherosclerosis [3]. This means that atherosclerosis in RA is multifactorial, not related to single hit but mostly a combination of factors including genetic polymorphism.

Large epidemiological studies from the last few decades have confirmed that patients with RA are $60 \%$ more likely to suffer a CV event than subjects from the general population. The major complication in patients with RA is the development of cardiovascular events due to accelerated atherosclerosis [4].

Large artery stiffness is known to be increased in patients with atherosclerosis and it is both a surrogate marker and an independent risk factor for atherosclerosis [5]. Aortic PWV (commonly the carotidfemoral PWV) is accepted as the gold standard measure of arterial stiffness. Brachial-ankle PWV (baPWV) is, however, a promising technique to measure arterial stiffness conveniently and more suited to routine clinical use than some other more intrusive or complicated approaches [6].

One of the non-invasive methods to assess subclinical atherosclerosis is carotid intima-media thickness (CIMT) and it has been recommended by the American Heart Association (AHA), American Society of Echocardiography (ASE) and Society for Vascular Medicine (SVM) as a screening test for heart disease in apparently healthy individuals [7]. Targońska-Stepniak et al., [8] concluded that Values of cIMT were significantly greater in RA compared with control subjects. Features of RA, such as extra-articular manifestations, erosions, high inflammatory parameters, and long disease duration, even in the absence of traditional clinical CV risk factors, were associated with greater cIMT, suggesting an unfavorable CV risk profile.

Endothelial dysfunction is an essential step in atherogenesis [9], and is recognized as an early and modulating process in the pathophysiology of atherosclerotic cardiovascular disease [10]. Most if not all risk factors that are related to cardiovascular disease (CVD) are also associated with endothelial dysfunction [9]. One of the methods to assess endothelial function involves the measurement of biomarkers of endothelial activation and dysfunction as circulating vascular cell adhesion molecule (VCAM)-1, intercellular adhesion molecule (ICAM)-1, and endothelial leukocyte adhesion molecule (ELAM)-1 [11].

Chung et al., [12] conclusion was little bite difference from many studies, they concluded that: The incidence and progression of CAC did not differ between RA and non-RA participants. In patients with $\mathrm{RA}$, incident CAC was associated with older age, higher triglyceride levels, and higher blood pressure, but not with inflammatory markers or RA disease characteristics, but this may be due to their selection of patients as they choose patients old in age, and this also make researcher don't neglect traditional risk factors for atherosclerosis [12], also with this idea, it can be suggested that people with comorbidities with rheumatoid arthritis as hypertension, diabetes are more vulnerable to atherosclerosis.

Wallberg-Jonsson et al., [13] concluded that treatment with methotrexate seemed to decrease the IMT-CCA, and this implicates the role of disease control in controlling atherosclerosis progression in RA [13]. However, Chen et al., [14] concluded from their study that there is Significant associations of RA-related inflammation with lipid profiles and insulin resistance indicate the involvement of RA in atherosclerosis pathogenesis, and that Biologic therapies were associated with IR reduction without change in atherogenic index, but their beneficial effects on atherosclerosis reduction need to be verified in the future [14], this raise the idea that methotrexate may still a corner stone in RA, not only controlling disease activity but also regress the atherosclerotic process, however the role of biologic in this area is debatable. As regards biologic effect on atherogenesis process; for example TNF inhibition in RA in spite of being the cardioprotective due to many aspect as, for example, the increase of HDL levels; therefore, these drugs do not affect LDL levels or atherosclerotic index (i.e., TC/HDL ratio) [15], and also it dramatic reduce resistin, an adipokine that showed strong correlation with Creactive protein [16], TNF inhibition can augment heart failure if used in severe heart failure [17]. Tocilizumab (TCZ) acts through the inhibition of IL-6, which is one of the cytokine that may contribute to atherosclerosis processes; TCZ improves endothelial function and aortic stiffness in RA patients, and this despite the increase of total and LDL-cholesterol [18]. Abatacept is a fully human soluble fusion protein consisting of the extracellular domain of human CTLA- 4 and the modified Fc portion of human IgG1; till now there is no data on the effects of this drug on atherosclerosis. Rituximab (RTX) is a chimeric monoclonal antibody against CD20 depleting B cells in peripheral blood; RTX has scanty data on its role in atherosclerosis regression, although, at least in short term, this drug seems to improve endothelial dysfunction, carotid atherosclerosis, and lipid profile in RA [19]. 


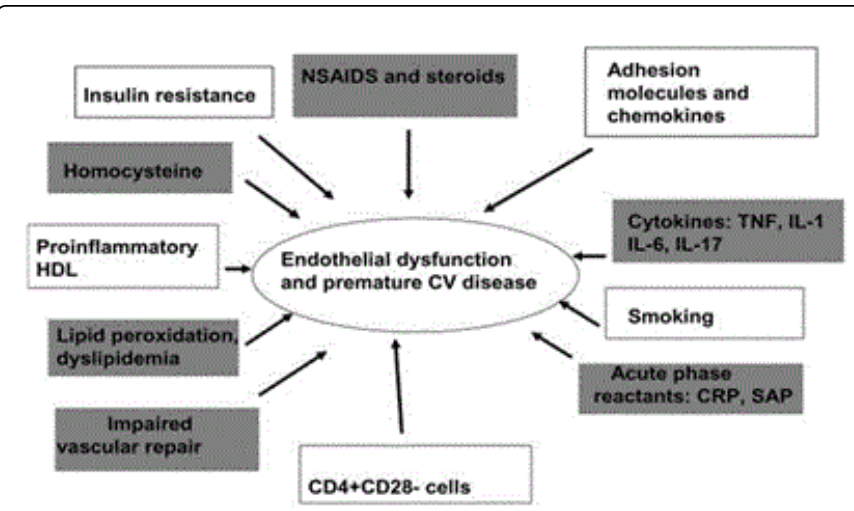

Figure 1: Showing etiology of endothelial dysfunction

This Figure 1 emphasis the contribution of different risk factors in endothelial dysfunction in patients with rheumatoid arthritis including genetic background, and inflammatory cytokines, all this raising a very important research point in how to reduce the progression of atherosclerosis in RA patients is it by controlling disease activity, or controlling risk factors, choice of medication, or you need all this to protect your patient from premature atherosclerosis. Also we need to standardize a follow up procedure for all RA patients to detect early atherosclerosis, and start management, I suggest more studies in this field to identify is only measuring of carotid intima media thickness, or pulse wave velocity is an enough tool to assess early atherosclerosis and arterial stiffness in RA patients or this must be accompanied by detection of different cytokines, in conjunction with genetic tests.

\section{References}

1. Wolfe F, Mitchell DM, Sibley JT, Fries JF, Bloch DA, et al. (1994) The mortality of rheumatoid arthritis. Arthritis Rheum 37: 481-494.

2. Nagata-Sakurai $M$, Inaba $M$, Goto $H$, Kumeda $Y$, Furumitsu $Y$, et al. (2003) Inflammation and bone resorption as independent factors of accelerated arterial wall thickening in patients with rheumatoid arthritis. Arthritis Rheum 48: 3061-3067.

3. Cavagna L, Boffini N, Cagnotto G, Inverardi F, Grosso V, et al. (2012) Atherosclerosis and Rheumatoid Arthritis: More Than a Simple Association. Mediators of Inflammation.

4. Meune C, Touzé E, Trinquart L, Allanore Y (2009) Trends in cardiovascular mortality in patients with rheumatoid arthritis over 50 years: a systematic review and meta-analysis of cohort studies. Rheumatology (Oxford) 48: 1309-1313.
5. Lakatta EG, Levy D (2003) Arterial and cardiac aging: major shareholders in cardiovascular disease enterprises: Part I: aging arteries: a "set up" for vascular disease. Circulation 107: 139-146.

6. Munakata MNT, Tayama J, Yoshinaga K, Toyota T (2005) BrachialAnkle pulse wave velocity as a novel measure of arterial stiffness: present evidences and perspectives. Curr Hypertens Rev 1: 223-234.

7. Greenland P, Alpert JS, Beller GA, Benjamin EJ, Budoff MJ, et al. (2010) American College of Cardiology Foundation/American Heart Association Task Force on Practice Guidelines Circulation. 122: e584-636.

8. Targonska-Stepniak B, Drelich-Zbroja A, Majdan M (2011) The relationship between carotid intima-media thickness and the activity of rheumatoid arthritis. J Clin Rheumatol 17: 249-255.

9. Bonetti PO, Lerman LO, Lerman A (2003) Endothelial dysfunction: a marker of atherosclerotic risk. Arterioscler Thromb Vasc Biol 23: 168-175.

10. Asselbergs FW, van der Harst P, Jessurun GA, Tio RA, van Gilst WH (2005) Clinical impact of vasomotor function assessment and the role of ACE-inhibitors and statins. Vascul Pharmacol 42: 125-140.

11. Meigs JB, Hu FB, Rifai N, Manson JE (2004) Biomarkers of endothelial dysfunction and risk of type 2 diabetes mellitus. JAMA 291: 1978-1986.

12. Chung CP, Giles JT, Kronmal RA, Post WS, Gelber AC, ET AL. (2013) Progression of coronary artery atherosclerosis in rheumatoid arthritis: comparison with participants from the Multi-Ethnic Study of Atherosclerosis. Arthritis Res Ther 15: R134.

13. Wållberg-Jonsson S, Ohman M, Rantapää-Dahlqvist S (2004) Which factors are related to the presence of atherosclerosis in rheumatoid arthritis? Scand J Rheumatol 33: 373-379.

14. Chen DY, Chen YM, Hsieh TY, Hsieh CW, Lin CC, et al. (2015) Significant effects of biologic therapy on lipid profiles and insulin resistance in patients with rheumatoid arthritis. Arthritis Res Ther 17:52.

15. Daïen CI, Duny Y, Barnetche T, Daurès JP, Combe B, et al. (2012) Effect of TNF inhibitors on lipid profile in rheumatoid arthritis: a systematic review with meta-analysis. Ann Rheum Dis 71: 862-868.

16. Gonzalez-Gay MA, Garcia-Unzueta MT, Gonzalez-Juanatey C, MirandaFilloy JA, Vazquez-Rodriguez TR, et al. (2008) Anti-TNF-alpha therapy modulates resistin in patients with rheumatoid arthritis. Clin Exp Rheumatol 26: 311-316.

17. Sarzi-Puttini P, Atzeni F, Shoenfeld Y, Ferraccioli G (2005) TNF-alpha, rheumatoid arthritis, and heart failure: a rheumatological dilemma. Autoimmun Rev 4: 153-161.

18. Atzeni F, Turiel M, Caporali R, Cavagna L, Tomasoni L, et al. (2010) The effect of pharmacological therapy on the cardiovascular system of patients with systemic rheumatic diseases. Autoimmun Rev 9: 835-839.

19. Kerekes G, Soltész P, Dér H, Veres K, Szabó Z, et al. (2009) Effects of rituximab treatment on endothelial dysfunction, carotid atherosclerosis, and lipid profile in rheumatoid arthritis. Clin Rheumatol 28: 705-710. 